\title{
Discrimination between Crigler-Najjar Type I and II by Expression of Mutant Bilirubin Uridine Diphosphate-Glucuronosyltransferase
}

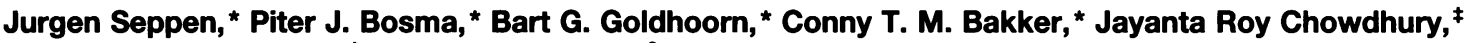 \\ Namita Roy Chowdhury, ${ }^{\ddagger}$ Peter L. M. Jansen, ${ }^{\S}$ and Ronald P. J. Oude Elferink* \\ ${ }^{*}$ Department of Gastrointestinal and Liver Diseases, Academic Medical Centre, 1105 AZ, Amsterdam, The Netherlands; ${ }^{\ddagger}$ Marion Bessin \\ Liver Research Centre, Albert Einstein College of Medicine, Bronx, New York 10461; and ${ }^{\S}$ Department of Gastroenterology and \\ Hepatology, Academic Hospital Groningen, 9700 RB, Groningen, The Netherlands
}

\begin{abstract}
Crigler-Najjar ( $\mathrm{CN}$ ) disease is classified into two subtypes, type I and II. The molecular basis for the difference between these types is not well understood.

Several mutations in the bilirubin UDP-glucuronosyltransferase (B-UGT) gene of six CN type I and two CN type II patients were identified. Recombinant cDNAs containing these mutations were expressed in COS cells. B-UGT activity was measured using HPLC and the amount of expressed protein was quantitated using a sandwich ELISA. This enabled us to determine the specific activities of the expressed enzymes. All type I patients examined had mutations in the B-UGT1 gene that lead to completely inactive enzymes. The mutations in the B-UGT1 gene of patients with $\mathrm{CN}$ type II only partially inactivated the enzyme. At saturating concentrations of bilirubin (75 $\mu \mathrm{M}$ ) $\mathrm{CN}$ type II patient A had $4.4 \pm 2 \%$ residual activity and $C N$ type II patient $B$ had $38 \pm 2 \%$ residual activity.

Kinetic constants for the glucuronidation of bilirubin were determined. The affinities for bilirubin of B-UGT1 expressed in COS cells and B-UGT from human liver microsomes were similar with $K_{\mathrm{m}}$ of $5.1 \pm 0.9 \mu \mathrm{M}$ and 7.9 \pm 5.3 $\mu M$, respectively. B-UGT1 from patient $B$ had a tenfold decreased affinity for bilirubin, $K_{\mathrm{m}}=56 \pm 23 \mu \mathrm{M}$.

At physiological concentrations of bilirubin both type II patients will have a strongly reduced conjugation capacity, whereas type I patients have no B-UGT activity. We conclude that $\mathrm{CN}$ type $I$ is caused by a complete absence of functional B-UGT and that in CN type II B-UGT activity is reduced. (J. Clin. Invest. 1994.94:2385-2391.) Key words: hereditary diseases - site directed mutagenesis - enzymelinked immunosorbent assay • enzyme kinetics • enzyme activity
\end{abstract}

\section{Introduction}

Crigler-Najjar disease $(\mathrm{CN})^{1}$ is a form of familial hyperbilirubinemia characterized by high serum levels of unconjugated

Address correspondence to Jurgen Seppen, Academic Medical Centre, Department of Gastrointestinal and Liver Diseases, FO-116, Meibergdreef 9, $1105 \mathrm{AZ}$ Amsterdam, The Netherlands.

Received for publication 25 April 1994 and in revised form 5 August 1994.

1. Abbreviations used in this paper: B-UGT, bilirubin UDP-glucuronosyltransferase; CN, Crigler-Najjar disease; DOPC, dioleoyl phosphatidylcholine; UGT1, human UGT1 gene.

J. Clin. Invest.

(C) The American Society for Clinical Investigation, Inc.

0021-9738/94/12/2385/07 \$2.00

Volume 94, December 1994, 2385-2391 bilirubin (1). The disease is caused by an absence or strong reduction of the activity of the hepatic enzyme bilirubin UDPglucuronosyltransferase (B-UGT) (EC 2.4.1.17). The CN syndrome can be divided into two subtypes; the more severe type I with high levels of serum bilirubin and the milder type II with lower levels of serum bilirubin and a reduction of these levels of more than $30 \%$ upon phenobarbital treatment (2-10). Bile of type II patients contains bilirubin glucuronides, though much less than bile of healthy controls (2-4).

Recently the human UGTI gene has been characterized at the molecular level (11). At least four different transcripts are generated from a single gene by a mechanism of alternative splicing. This mechanism produces isoforms of UGT with transferase activity towards bilirubin and phenolic substrates. All $U G T 1$ gene products share an identical carboxyl terminal domain. This constant domain probably contains the $U D P$-glucuronic acid binding site and the putative transmembrane helix. Mutations located in this constant part of the UGT1 locus will affect all isoenzymes. The $U G T 1$ gene products have an unique amino terminal domain, termed exons UGTIA to $U G T I F$, which are responsible for the substrate specificity $(11,12)$.

Two UGT isoforms (B-UGT1 and B-UGT2, the products of the UGTIA and UGTID exons) have been postulated to mediate bilirubin glucuronidating activity (11).

To investigate the molecular basis for the difference between CN type I and II we identified mutations in the variable and the constant part of the bilirubin UGT1 gene of CN type I and II patients (13-15) and expressed these mutant enzymes in COS cells.

\section{Methods}

\section{Patients}

Two CN type II patients and six $\mathrm{CN}$ type I patients were studied. Clinical features of these patients are described below and are summarized in Table I. Mutations present in these patients are described in Table I.

CN type II patients. Patient A was diagnosed as a type II and described in reference 15 . The patient is a 40-yr-old male. 1 mo after birth his serum bilirubin level was $85 \mu \mathrm{M}, 3$ mo after birth his serum bilirubin had risen to $194 \mu \mathrm{M}$. At the ages of 29 and $40 \mathrm{yr}$ serum bilirubin levels were 286 and $342 \pm 23 \mu \mathrm{M}$, respectively. When fasting for $24 \mathrm{~h}$ serum bilirubin was increased with $43 \%$. Phenobarbital treatment resulted in a $36 \%$ decrease in serum bilirubin. Bilirubin decreased from 279 to 218 $\mu \mathrm{M}$ when treated for 1 wk with $50 \mathrm{mg}$ phenobarbital/d and from 218 to $179 \mu \mathrm{M}$ on a dose of $100 \mathrm{mg} / \mathrm{d}$ during $1 \mathrm{wk}$.

Patient B became jaundiced directly after birth. Phototherapy reduced the serum bilirubin from 470 to $200 \mu \mathrm{M}$. A duodenal bile sample was collected at an age of 5 wk. The bile was analyzed using HPLC. Unconjugated and conjugated bilirubin were detected, the composition was $5 \%$ bilirubin diconjugate, $30 \%$ bilirubin mono conjugate and $65 \%$ unconjugated bilirubin. Total bilirubin concentration in the sample, which contained $\sim 50 \%$ bile, was $36 \mu \mathrm{M}$.

The patient was treated with phenobarbital at an age of $1 \mathrm{yr}$, which 
resulted in a moderate response. When a dose of $5 \mathrm{mg} / \mathrm{kg}$ body wt was given for $1 \mathrm{wk}$ serum bilirubin dropped from 120 to $87 \mu \mathrm{M}$. A week after the treatment was halted serum bilirubin was $92 \mu \mathrm{M}$.

At an age of $4 \mathrm{yr}$ the patient receives $4 \mathrm{~h}$ of light therapy per $\mathrm{d}$ with 1220 -W tubes, with this treatment serum bilirubin levels range between 100 and $130 \mu \mathrm{M}$. Since her serum bilirubin is kept at a relatively low level with only limited treatment and because a significant amount of bilirubin glucuronides were detected in bile she was classified as type II, despite the limited phenobarbital response.

$C N$ type I patients. Patient $\mathrm{C}$ at the age of 16 , underwent an orthotopic liver transplantation. Before transplantation bilirubin levels were around $400 \mu \mathrm{M}$ and she did not respond to phenobarbital treatment (13). A liver specimen did not contain detectable B-UGT activity (16).

Patients D and E both underwent orthotopic liver transplantation (14). Diagnosis of CN type I was based on high serum bilirubin levels, $460 \mu \mathrm{M}$ in patient $\mathrm{D}$ and $430 \mu \mathrm{M}$ in patient $\mathrm{E}$. There was no response to phenobarbital treatment. Bile of patient $E$ did not contain detectable amounts of bilirubin conjugates. Liver specimens did not contain any detectable B-UGT activity.

A clinical and immunological description of patients $F$ and $G$ was given (16), where these patients were termed $C$ and $D$, respectively. Both patients underwent orthotopic liver transplantation. Patient $\mathrm{F}$ was a 3-yr-old (at the time of study) female with an average serum bilirubin of $430 \mu \mathrm{M}$. Patient $\mathrm{G}$ was a 9-yr-old (at the time of study) female with an average serum bilirubin of $420 \mu \mathrm{M}$. Liver specimens of both patients did not contain detectable B-UGT activity. Diagnosis of CN type I was based on high serum bilirubin levels and lack of phenobarbital response.

Patient $\mathrm{H}$ is a 16-yr-old boy in whom jaundice was noted soon after birth. On phototherapy, serum bilirubin levels varied from 340 to 425 $\mu \mathrm{M}$. At the age of 15 , he started experiencing difficulty in learning and had subtle motor abnormalities. There was no response to phenobarbital. $\mathrm{He}$ underwent orthotopic liver transplantation, which reversed the neurological abnormalities. Hepatic B-UGT activity was undetectable.

\section{Chemicals}

DOPC was obtained from Avanti Polar Lipids, Inc. (Birmingham, AL). UDP-glucuronic acid and Triton X-100 from Boehringer (Mannheim, Germany). Bilirubin and cell dissociation solution from Sigma Chemical Co. (St Louis, MO). Nitro blue tetrazolium, 5-bromo, 4-chloro, 3indoyl phosphate, acrylamide, bis acrylamide, goat anti-mouse alkaline phosphatase, goat anti-rabbit alkaline phosphatase, and goat antimouse peroxidase from Biorad (Veenendaal, The Netherlands). pSVK3 and DEAE dextran were from Pharmacia (Uppsala, Sweden). Nitrocellulose membranes $0.45 \mu \mathrm{m}$ pore size from Schleicher and Schuell (Dassel, Germany). $3^{\prime}, 3^{\prime}, 5^{\prime}, 5^{\prime}$ Tetramethylbenzidine was from Fluka Chemie AG (Buchs Switzerland). Cromspher 5, C18, $100 \times 10 \mathrm{~mm}$, reverse phase column was from Chrompack (Middelburg, The Netherlands). Slide Write plus 5, from Advanced Graphics Software, Inc. (Carlsbad, CA).

All other chemicals were of analytical grade and obtained from E. Merck (Darmstadt, Germany).

\section{Identification of mutations, site directed mutagenesis, and expression of recombinant $B-U G T$ cDNAs in COS cells}

Identification of mutations was performed as described previously (1315). B-UGT1 cDNAs were cloned in the EcoRI and ApaI restriction sites of pSVK3. Site-directed mutagenesis was performed as described in (17). Plasmids were isolated using Qiagen and sequenced completely to confirm the introduction of the mutations and to exclude abnormalities.

COS cells were transfected using DEAE dextran. Cells grown in $162-\mathrm{cm}^{2}$ culture bottles were incubated $4 \mathrm{~h}$ at $37^{\circ} \mathrm{C}$ in a $10 \% \mathrm{CO}_{2}$ atmosphere with $9 \mathrm{ml}$ optimum medium containing $2 \mathrm{mg} / \mathrm{ml}$ DEAE dextran, $100 \mu \mathrm{M}$ chloroquine, and $10 \mu \mathrm{g}$ of plasmid DNA. The medium was removed and the cells were treated for $2.5 \mathrm{~min}$ with $10 \%$ DMSO in PBS. The cells were washed twice with DME and grown for 2-3 d in DME containing $10 \%$ fetal calf serum. Cells were harvested using cell dissociation solution and washed twice with $5 \mathrm{mM}$ Mops $\mathrm{pH}$ 7.0, $250 \mathrm{mM}$ mannitol, and $2 \mathrm{mM}$ EGTA. The cells were incubated for 15 min at $4^{\circ} \mathrm{C}$ in this buffer and disrupted with 25 strokes of a dounce. Nuclei and large debris were removed by centrifugation for $5 \mathrm{~min}$ at $7,000 \mathrm{~g}$. The microsomal fraction was pelleted by centrifuging for $1 \mathrm{~h}$ at $100,000 \mathrm{~g}$. COS cell microsomes were resuspended in $50 \mathrm{mM}$ Hepes $\mathrm{pH} 7.8,2 \mathrm{mM}$ EDTA, and $20 \%$ glycerol (buffer A) and stored at $-20^{\circ} \mathrm{C}$.

Human liver microsomes were isolated as described (18), resuspended in buffer $\mathrm{A}$ and stored at $-70^{\circ} \mathrm{C}$.

\section{Quantitation of B-UGT expression}

Microtiter plates were coated overnight with the monoclonal antibody WP1 (18) diluted 1:4000 in PBS. The plates were blocked with $1 \%$ bovine serum albumin in PBS for $2 \mathrm{~h}$ at $37^{\circ} \mathrm{C}$. Different UGT containing preparations were solubilized with $1 \%$ Triton $\mathrm{X}-100$ in deionized water for $1 \mathrm{~h}$ at $4^{\circ} \mathrm{C}$, diluted 10 times with $0.1 \%$ Triton $\mathrm{X}-100,1 \% \mathrm{BSA}$ in PBS (buffer B), and applied to the microtiter plate for further dilution. Microsomal samples were diluted 20-320 times in buffer B, all samples were applied in triplicate. Standard immunopurified UGT was processed in the same way except that twofold dilutions from 20 to 20,960 times were used.

Binding was allowed to proceed for $2 \mathrm{~h}$ at $37^{\circ} \mathrm{C}$. The plate was washed with PBS containing $0.05 \%$ Tween 20 . As secondary antibody a polyclonal serum raised against immunopurified human UGT (16) was used. The serum was diluted 1:500 in PBS 0.1\% Triton X-100, 1\% $\mathrm{BSA}$, and incubated for $2 \mathrm{~h}$ at $37^{\circ} \mathrm{C}$. The plate was washed with PBS, $0.05 \%$ Tween 20 . The presence of the polyclonal antibody was detected with goat anti-rabbit immunoglobulins conjugated with horseradish peroxidase. This antibody conjugate had been previously incubated with the monoclonal antibody WP1 to minimize the background. The conju-

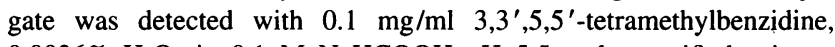
$0.0036 \% \mathrm{H}_{2} \mathrm{O}_{2}$ in $0.1 \mathrm{M} \mathrm{NaHCOOH} \mathrm{pH} 5.5$ and quantified using a EASIA reader, (Medgenix Diagnostics BV, Soesterberg, The Netherlands). The amount of UGT1 present in the samples was calculated by constructing a standard curve from the titration of the isolated human UGT and fitting this curve with the softmax program, supplied with the EASIA reader.

\section{Assay of B-UGT activity}

DOPC liposomes were prepared in $10 \mathrm{mM}$ Hepes $\mathrm{pH} 7.8,150 \mathrm{mM}$ $\mathrm{NaCl}$, by sonication (19), centrifuged at $4000 \mathrm{~g}$ for $10 \mathrm{~min}$ to remove titanium particles, stored at $4^{\circ} \mathrm{C}$ under argon, and used within $2 \mathrm{wk}$.

Human liver microsomes or COS cell microsomes (100-300 $\mu \mathrm{g}$ protein) were incubated with DOPC liposomes for $30 \mathrm{~min}$ at $4^{\circ} \mathrm{C}$ before the assay. Concentrations in the reaction mixture were $50 \mathrm{mM}$ Tris $\mathrm{HCl}$ $\mathrm{pH} 7.8,5 \mathrm{mM} \mathrm{MgCl}_{2}, 3.5 \mathrm{mM}$ UDPGA, $1 \mathrm{mM} \mathrm{1,4}$ saccharolactone, $2.5 \mathrm{mg} / \mathrm{ml}$ DOPC SUV, and 2.5-75 $\mu \mathrm{M}$ bilirubin in a total volume of $400 \mu \mathrm{l}$. Incubations were performed under argon in the dark at $37^{\circ} \mathrm{C}$ for $10 \mathrm{~min}$ up to $4 \mathrm{~h}$. All manipulations with bilirubin were performed in the dark or under dimmed light. Bilirubin solutions were prepared as follows: $2.9 \mathrm{mg}$ of bilirubin was dissolved in $1.25 \mathrm{ml} 50 \mathrm{mM} \mathrm{NaOH}$ by vortexing until the solution was optically clear, and neutralized by the addition of $3.75 \mathrm{ml}$ of $100 \mathrm{mM}$ Tris $\mathrm{HCl} \mathrm{pH} \mathrm{7.8.} \mathrm{Bilirubin} \mathrm{solutions}$ were used within $5 \mathrm{~min}$ after preparation. For the determination of initial rates of bilirubin glucuronide formation a concentration range of 2.5-40 $\mu \mathrm{M}$ bilirubin was used. Maximal $15 \%$ of bilirubin was glucuronidated at the lowest concentrations of bilirubin employed. Reactions were stopped and bilirubin and conjugates were extracted by a modification of an existing procedure [20]. First a dash of ascorbic acid was added to the reaction vessels, subsequently $1.4 \mathrm{ml}$ of chloroform/ethanol 1:1 (vol/ vol) and $1 \mathrm{ml}$ of $0.4 \mathrm{M} \mathrm{HCl}$ adjusted to $\mathrm{pH} 1.8$ with solid glycine was added and the mixture was vortexed vigorously. The tubes were centrifuged at $3000 \mathrm{rpm}$ for $5 \mathrm{~min}$. The lower colored phase was aspirated and transferred to a glass tube. The chloroform was immediately evaporated under a stream of nitrogen. Samples were stored under argon in the dark at $-20^{\circ} \mathrm{C}$ for up to $2 \mathrm{~d}$. The time needed from extraction to storage was less than $30 \mathrm{~min}$. The percentage of bilirubin conjugated was determined using reverse phase HPLC (21). Bilirubin and bilirubin conjugates were dissolved in $100 \mu \mathrm{l}$ chloroform/ethanol 1:1 ( $\mathrm{vol} / \mathrm{vol})$, $20 \mu \mathrm{l}$ was injected onto a HPLC system equipped with a chromsep C18 column within 5 min after dissolving. Elution was monitored at $450 \mathrm{~nm}$ 
using a diode array detector; to confirm the identity of the peaks spectra were examined.

The percentage of bilirubin conjugated was calculated by determining the integrated peak areas.

\section{Calculation of kinetic parameters}

The contribution of diglucuronides to the total amount of glucuronides was highest at low bilirubin concentrations but never exceeded $10 \%$. Since B-UGT has the same affinity for unconjugated bilirubin as for monoglucuronide and since both are competitors for the same binding site (22), diglucuronides were treated as two monoglucuronides.

Substrate concentration and the initial rates of glucuronide formation were fitted directly to the Michaelis-Menten equation using the 1 site ligand binding curve fitting option in slide write plus 5.0 to obtain the kinetic parameters.

\section{Protein electrophoresis and Western blotting}

SDS PAGE was performed according to (23) on a Hoeffer Scientific instruments Mighty Small II system. Western blotting of the separated proteins on a nitrocellulose membrane was carried out in a electroblotting apparatus. UGT was visualized with mouse ascites containing the monoclonal antibody WP1 (18) or a polyclonal serum, 6215. Goat antirabbit or mouse immunoglobulins conjugated with alkaline phosphatase were used as secondary antibodies. The presence of the conjugate was detected with $0.33 \mathrm{mg} / \mathrm{ml}$ nitro blue tetrazolium and $0.17 \mathrm{mg} / \mathrm{ml} \mathrm{5-}$ bromo-4-chloro-3-indoyl phosphate in $100 \mathrm{mM}$ Tris pH 9.5, $100 \mathrm{mM}$ $\mathrm{NaCl}$, and $5 \mathrm{mM} \mathrm{MgCl}$.

Protein was determined with fluorescamine (24) using bovine serum albumin as a standard.

\section{Results}

Quantitation of recombinant B-UGT expressed in COS cells. Wild type B-UGT1 and B-UGT2 cDNA and B-UGT1 cDNAs

Table I. Summary of Clinical and Biochemical Data from CN Patients Described in This Study

\begin{tabular}{|c|c|c|c|c|c|c|}
\hline Patient & $\begin{array}{l}\mathrm{CN} \\
\text { type }\end{array}$ & $\begin{array}{l}\text { Average } \\
\text { serum } \\
\text { bilirubin }\end{array}$ & $\begin{array}{l}\text { Mutation } \\
\text { DNA }\end{array}$ & $\begin{array}{l}\text { Mutation } \\
\text { Protein }\end{array}$ & $\begin{array}{l}\text { B-UGT } \\
\text { activity } \\
\text { in liver }\end{array}$ & $\begin{array}{c}\text { Activity of } \\
\text { B-UGT1 }\end{array}$ \\
\hline & & $\mu M$ & & & & \\
\hline A & 2 & 340 & $\begin{array}{l}\text { NT } 625 \\
T \rightarrow C\end{array}$ & $\begin{array}{l}\text { AA } 209 \\
\text { arg } \rightarrow \text { tryp }\end{array}$ & ND & Yes \\
\hline B & 2 & 140 & $\begin{array}{l}\text { NT } 524 \\
\text { T } \rightarrow \text { A } \\
\text { Del } \\
\text { NT } 973\end{array}$ & $\begin{array}{l}\text { AA } 175 \\
\text { leu } \rightarrow \text { glu } \\
\text { frameshift }\end{array}$ & ND & $\begin{array}{l}\text { Yes } \\
\text { ND }\end{array}$ \\
\hline $\mathrm{C}$ & 1 & 410 & $\begin{array}{l}\text { NT } 1069 \\
C \rightarrow T\end{array}$ & $\begin{array}{l}\text { AA } 356 \\
\text { stop }\end{array}$ & No & ND \\
\hline D & 1 & 460 & $\begin{array}{l}\text { NT } 1130 \\
\mathrm{C} \rightarrow \mathrm{T}\end{array}$ & $\begin{array}{l}\text { AA } 375 \\
\text { ser } \rightarrow \text { phe }\end{array}$ & No & No \\
\hline E & 1 & 430 & $\begin{array}{l}\text { Del } \\
\text { exon } 2\end{array}$ & & No & ND \\
\hline $\mathrm{F}$ & 1 & 430 & $\begin{array}{l}\text { Del NT } \\
508-510\end{array}$ & $\begin{array}{l}\text { Del AA } \\
170 \text { phe }\end{array}$ & No & No \\
\hline G & 1 & 420 & $\begin{array}{l}\text { NT } 826 \\
G \rightarrow T\end{array}$ & $\begin{array}{l}\text { AA } 276 \\
\text { gly } \rightarrow \text { arg }\end{array}$ & No & No \\
\hline H & 1 & 380 & $\begin{array}{l}\text { NT } 529 \\
T \rightarrow C \\
\text { Del NT } \\
879-892\end{array}$ & $\begin{array}{l}\text { AA } 177 \\
\text { cys } \rightarrow \text { arg } \\
\text { Frameshift }\end{array}$ & No & $\begin{array}{l}\text { No } \\
\text { ND }\end{array}$ \\
\hline
\end{tabular}

Patients $\mathrm{B}$ and $\mathrm{H}$ are heterozygotes. Truncated proteins or proteins with a frameshift were not expressed. ND, not done; AA, amino acid residue; Del, deletion; NT, nucleotide.

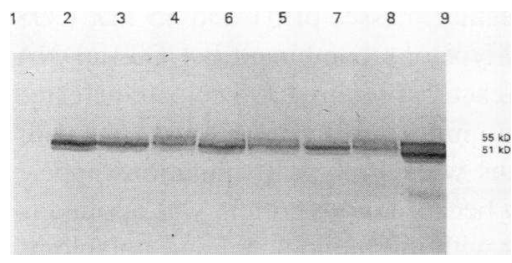

Figure 1. SDS PAGE and Western blotting of microsomes from transfected COS cells. Microsomes from COS cells transfected with various B-UGT1 cDNAs and human liver microsomes were subjected to SDS PAGE, and Western blotting was performed with a polyclonal antiserum directed against human UGT. 35$100 \mu \mathrm{g}$ protein were applied to each lane. Lane 1 , control COS cells; lane 2, B-UGT1; lane 3, patient F; lane 4, patient G; lane 5, patient $\mathrm{H}$; lane 6 , patient $\mathrm{D}$; lane 7 , patient $\mathrm{B}$; lane 8 , patient $\mathrm{A}$; lane 9 , human liver microsomes.

with the mutations described in Table I were expressed in COS cells. Microsomal fractions of the cells were subjected to SDS PAGE and Western blotting. UGT was detected using a polyclonal serum raised against human UGT. In Fig. 1 a Western blot is shown with the expressed proteins used for this study. The recombinant proteins appear identical, they have the same electrophoretic mobility and no signs of degradation are seen.

To investigate whether the UGT antibodies available to us were suitable to develop a quantitative sandwich ELISA, we subjected two identical gels to Western blotting with two different antibodies. This is shown in Fig. 2. B-UGT was visualized with the monoclonal antibody WP1, which is directed against the common region of all UGTl encoded enzymes and with a polyclonal antibody raised against immunopurified human UGT (18).

Human liver microsomes contain two immunoreactive

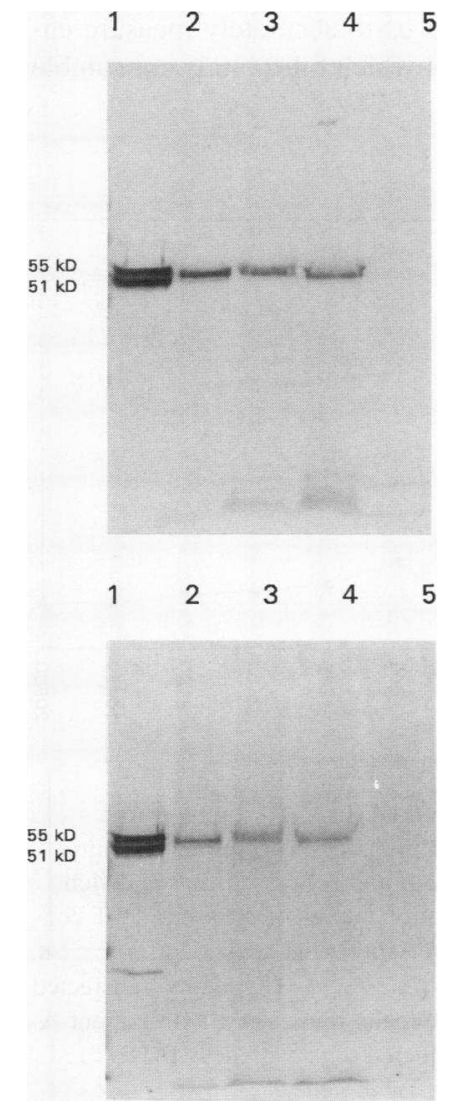

Figure 2. SDS PAGE and Western blotting of microsomes from transfected COS cells. Human liver microsomes and microsomes from COS cells transfected with B-UGT1 cDNAs from normal and $\mathrm{CN}$ type II patients, and from cells transfected with the lac $\mathrm{Z}$ gene, were subjected to SDS PAGE and Western blotting with the monoclonal antibody WPI and a polyclonal antibody. Two identical gels are shown. (Upper panel) UGT detected with the monoclonal antibody, (Lower panel) UGT detected with the polyclonal antibody. Lane $I, 15$ $\mu \mathrm{g}$ human liver microsomes; lane 2, $18 \mu \mathrm{g}, \mathrm{B}-\mathrm{UGT} 1$; lane 3 , $42 \mu \mathrm{g}, \mathrm{B}-\mathrm{UGT} 1$ patient $\mathrm{A}$; lane $4,51 \mu \mathrm{g}, \mathrm{B}-\mathrm{UGT} 1$ patient $\mathrm{B}$ : lane $5,23 \mu \mathrm{g}$ lacZ gene. 
UGTs with apparent molecular masses of 51 and $55 \mathrm{kD}$, COS cells transfected with wild type or recombinant B-UGT1 cDNA contain only one immunoreactive protein. COS cells transfected with the lac $\mathrm{Z}$ gene show no immunoreactivity at all. The bands of the recombinant proteins with the type II mutations appear somewhat fuzzy, probably because more protein was applied in these lanes. Western blots with the monoclonal and polyclonal antibody essentially show the same pattern. We concluded that both antibodies reacted with wild type and recombinant proteins and could be used to develop a quantitative ELISA.

The monoclonal antibody was used to coat microtiter plates. UGT is a membrane protein and had to be solubilized with $1 \%$ Triton X-100 before binding to the antibody-coated plate could take place. To prevent reconstitution during dilution of UGT $0.1 \%$ Triton X-100 was included in the dilution buffer. A preparation of immunopurified UGT (16) processed in the same way as the microsomal samples from the COS cells was used as a standard. The polyclonal antibody was used to detect UGT that bound to the immobilized monoclonal antibody.

Fig. 3 shows the titration of immunopurified standard UGT and microsomes from-COS cells transfected with normal or recombinant UGT cDNA. As a control titration of COS cells transfected with the lac $\mathrm{Z}$ gene is shown. The titration curves have the same slope, indicating that the binding affinity of the antibodies is not affected by the mutations. This sandwich ELISA was used to quantitate the amount of UGT that was present in the transfected COS cells.

Quantitation of B-UGT activity. Bilirubin is poorly soluble in water but readily dissolves in membranes (25). It also associates rapidly with preformed liposomes $(26,27)$. The bilirubin liposome complex is a good substrate for B-UGT (28). Furthermore, dioleoyl phosphatidylcholine (DOPC) is a good activator of UGT (29), therefore a high concentration of DOPC liposomes was used in our assay system, this served not only to activate B-UGT but also enabled us to accurately measure enzyme activity at concentrations at which bilirubin is not soluble in water.

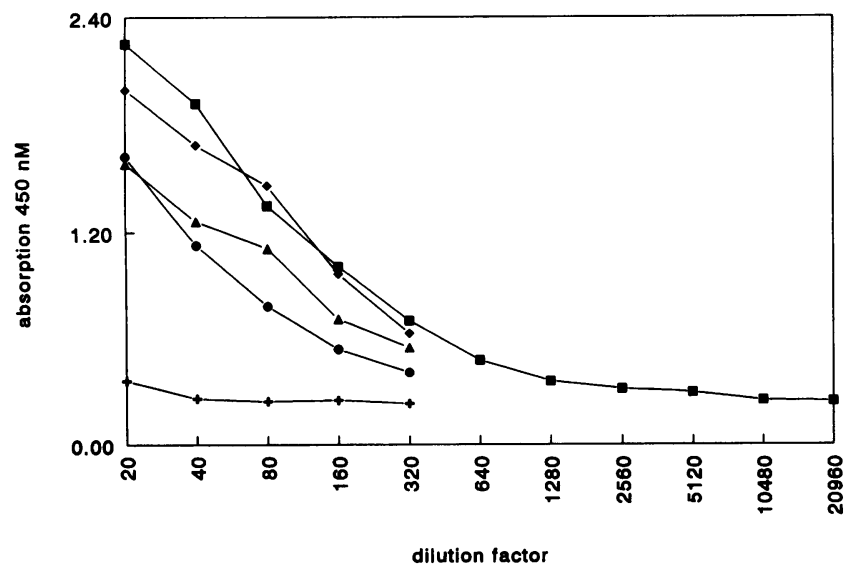

Figure 3. Sandwich ELISA for human UGT. Microsomes from transfected COS cells and a standard preparation of immunoaffinitypurified UGT were solubilized, diluted, and processed for sandwich ELISA as indicated in Methods. Titration curves of different UGT containing preparations in a representative experiment are shown. $\mathbf{\square - a}$, immunoaffinity-purified human UGT; $\bullet-\bullet$, COS cells transfected with normal B-UGT1; $\bullet-\bullet$, COS cells transfected with patient A B-UGT1; $\triangle \triangle$, COS cells transfected with patient B B-UGT1; ,$+-+ \operatorname{COS}$ cells transfected with lac $\mathrm{Z}$ gene.
Table II. Specific B-UGT Activities of Wild Type B-UGT1 and of B-UGTI from CN Type II Patients Expressed in COS Cells

\begin{tabular}{lc}
\hline & B-UGT Activity \\
\hline & pmol/min $\mu g$ B-UGT \\
Normal B-UGT1 & $25 \pm 5$ \\
Patient A B-UGT1 & $1.1 \pm 0.5$ \\
Patient B B-UGT1 & $9.6 \pm 0.5$
\end{tabular}

Specific activities of B-UGTs were obtained as follows: bilirubin conjugating activity in microsomal fractions from COS cells transfected with the indicated cDNAs was determined as described in Methods and the amount of expressed B-UGT1 in these fractions was measured by sandwich ELISA. Specific activities are expressed as pmol bilirubin glucuronide/min $\mu \mathrm{g}$ UGT. Bilirubin concentration in the assay mixture was 75 $\mu \mathrm{M}$. Values are the means \pm SD from three separate experiments.

B-UGT activity was measured by HPLC and the amount of B-UGT polypeptide present in the fractions used for the BUGT assay was measured by sandwich ELISA. In this way the specific activities of the expressed B-UGTs could be calculated.

The following control experiments were performed, prolonged incubations with microsomes from untreated COS cells and from COS cells transfected with the Escherichia coli $\beta$ galactosidase gene and incubations with COS cell microsomes transfected with normal and mutant B-UGT without UDPglucuronate. In all these cases no bilirubin mono- or diglucuronide peaks were seen in the HPLC chromatograms.

When B-UGT2 cDNA was expressed in COS cells, enzyme was produced which had less than $0.1 \%$ activity when compared to expressed B-UGT1.

All B-UGT1 cDNAs from type I patients expressed in COS cells yielded inactive enzyme. Even after prolonged incubation times, up to $4 \mathrm{~h}$, no activity was detectable. We did not express cDNAs which would give rise to truncated proteins.

With B-UGT1 cDNA from type II patients, enzyme was produced with partial activity. At a substrate concentration of $75 \mu \mathrm{M}$ bilirubin, cDNA derived from patient $\mathrm{A}$ was found to encode for an enzyme with $4.4 \pm 2 \%$ residual activity and cDNA from patient $B$ for an enzyme with $38 \pm 2 \%$ residual activity. These percentages are expressed relative to the specific activity of the wild type enzyme. In Table II the specific activities of wild type and mutated, type II B-UGT1s are summarized. Values for the specific activities are mean \pm SD from three separate experiments.

Although patient B has only one functional allele, the high residual activity can not explain the elevated serum bilirubin levels observed in this patient. To investigate this further we determined the affinity of normal and mutant protein for bilirubin by measuring the activity at different substrate concentrations. The results are depicted in Table III. Values were obtained from three separate experiments. Double reciprocal plots of initial rates of glucuronide formation (1/V) versus bilirubin concentration $(1 / \mathrm{S})$ from a representative experiment are shown in Fig. 4. Kinetic parameters of expressed normal BUGT1 and human liver microsomes are virtually identical. The observed $K_{\mathrm{m}}$ values agree with previously published data $\left(K_{\mathrm{m}}\right.$ $=13.7 \mu \mathrm{M})$ although assay conditions and detection method employed were different (22). The mutation from patient B causes a 10-fold increase in the apparent $K_{\mathrm{m}}$ for bilirubin when compared to expressed B-UGT1 or human liver microsomes. 
Table III. Kinetic Parameters for Bilirubin Glucuronidation in Wild Type B-UGT1 and Recombinant B-UGT1 from Patient B Expressed in COS Cells and from Human Liver Microsomes

\begin{tabular}{lcc}
\hline & $K_{\mathrm{m}}$ & $V_{\max }$ \\
\hline$\mu M$ & pmol/min $\mu g$ B-UGT \\
Human liver microsomes & $7.9 \pm 5.3$ & $\mathrm{ND}$ \\
Normal B-UGT1 & $5.1 \pm 0.9$ & $65 \pm 22$ \\
Patient B B-UGT1 & $56 \pm 23$ & $39 \pm 23$
\end{tabular}

Microsomal fractions were incubated with different bilirubin concentrations and the initial rates of bilirubin glucuronide formation were determined using HPLC. These data were fitted to the MichaelisMenten equation and the $\mathrm{V}_{\max }$ and $K_{\mathrm{m}}$ were calculated. Data represent means \pm SD from three separate experients. ND, not done.

Interestingly this mutation causes only a small alteration in the $V_{\max }$, an indication that only the binding of bilirubin is affected. Thus, at a physiological concentration of bilirubin, this type II patient will have a markedly reduced ability to glucuronidate bilirubin, whereas a significant level of residual activity is observed at the relatively high bilirubin concentration used in the in vitro assay.

\section{Discussion}

Crigler-Najjar disease can be divided in two subtypes, type I and II. The discrimination between these types is based upon the following clinical criteria: in type II, phenobarbital treatment lowers serum bilirubin levels with more than $30 \%$ and bilirubin glucuronides are present in bile. Type I patients do not respond to phenobarbital treatment and only traces of bilirubin glucuronides can be found in their bile (2). Analysis of liver material from biopsies or tissue removed during transplantation has revealed that in type I liver no B-UGT activity is present, whereas in type II liver sometimes a small residual activity can be observed (2-10). Until now it was not clear which enzyme was responsible for this activity.

Some heterogeneity in the clinical manifestation of $\mathrm{CN}$ type II is observed (2-10). Phenobarbital response varies between 27 and $78 \%$ and serum bilirubin levels can vary between 340 and $100 \mu \mathrm{M}$. The similarity between all type II patients is that symptoms are less severe than in type I and that usually no treatment is needed. However, patients have been described who could not be classified by the existing criteria, $\mathrm{CN}$ type II patients with bilirubin-induced neurological damage have been reported $(30,31)$ and a patient has been described who could not be classified at all (32).

The cloning and characterization of the UGT1 gene has led to the discovery of a rapidly accumulating array of mutations present in the B-UGT1 gene of patients with the CN syndrome $(13-15,33,34)$. The role these different point mutations might play in the development of the subtypes of the $\mathrm{CN}$ syndrome has not been investigated so far.

In this study we examined several $\mathrm{CN}$ type I and II patients and identified the mutations present in the B-UGT1 gene of these patients. Subsequently the effect these mutations have on the specific B-UGT enzyme activity was determined.

When cDNAs from the $\mathrm{CN}$ type I patients described in this study were transfected in COS cells, inactive B-UGTs were produced. Patient A, diagnosed as CN type II, has a B-UGT1

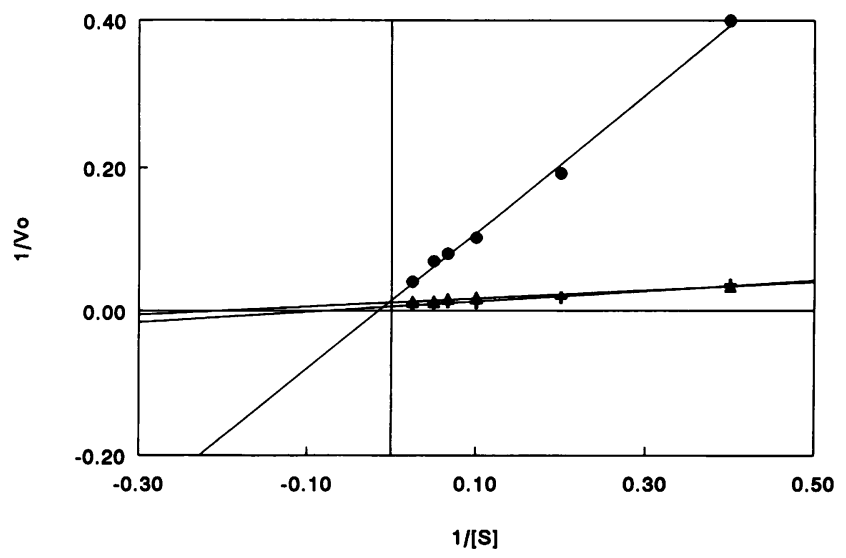

Figure 4. Lineweaver-Burk plots of bilirubin glucuronide formation. Reciprocal plots of bilirubin glucuronide formation versus bilirubin concentration. $S$ is in $\mu \mathrm{M}$ bilirubin and $V_{\mathrm{o}}$ is in pmol bilirubin glucuronide/ min. $\mu \mathrm{g}$ B-UGT. Assay of B-UGT activity was as described in Methods.

Human liver microsomes $(+-+)$, COS cells transfected with normal B-UGT1 cDNAs $(\Lambda-\Lambda)$, and COS cells transfected with cDNA from patient $\mathrm{B}(\bullet-\bullet)$. Data from three separate experiments were used to determine the kinetic parameters. A representative experiment is shown.

gene that gave rise to an enzyme with $4.4 \%$ residual activity, serum bilirubin levels are elevated to $340 \mu \mathrm{M}$, but the patient is currently without any treatment. Patient $\mathrm{B}$, also diagnosed as type II, has a B-UGT1 gene that gave rise to an enzyme with reduced activity as well. The reduction of B-UGT activity in this patient was caused by a 10 -fold decreased affinity for bilirubin of B-UGT1. This will result in an approximately ten-fold reduction in the glucuronidation capacity at physiological bilirubin concentrations well below the $K_{\mathrm{m}}$. At high concentrations of bilirubin, B-UGT activity will approach a normal value. This may explain why the serum bilirubin level is relatively low in this patient. With only limited treatment serum bilirubin levels are elevated to a value of only $100-130 \mu \mathrm{M}$.

Several lines of evidence argue against a role of B-UGT2 in the development of $\mathrm{CN}$ syndrome. The common carboxy terminal regions of both B-UGT1 and B-UGT2 are derived from the four shared exons at the $3^{\prime}$ region of the $U G T 1$ gene. As a consequence, mutations in any one of these exons will be present in both B-UGT isoforms. In this study such a mutation was found in patient $\mathrm{D}$. When a mutation is present in the unique exon encoding the $\mathrm{NH}_{2}$ terminal region of B-UGT1 (UGT1A), B-UGT2 mRNA is not affected. This is the case in patients F, G, and $\mathrm{H}$. Nevertheless B-UGT activity was absent in liver material of all these patients, suggesting that B-UGT2 does not contribute significantly to bilirubin conjugation in these patients. Furthermore we have shown that the specific activity of B-UGT2 is less than $0.1 \%$ of the activity of B-UGT1 (35). It is also known that B-UGT2 mRNA is expressed at a lower level than B-UGT1 mRNA (11). Together these arguments strongly suggest that B-UGT1 accounts for practically all bilirubin glucuronidating activity in human liver (35).

These data give rise to the following model: the development of $\mathrm{CN}$ disease is entirely governed by the presence of mutations in the B-UGT1 gene. Mutations in the constant or variable region that give rise to inactive enzymes result in $\mathrm{CN}$ type I. When the enzyme is only partially inactivated $\mathrm{CN}$ type II is developed. 
The mechanism by which phenobarbital reduces serum bilirubin of $\mathrm{CN}$ type II patients is complex, probably more than one pathway is involved. In the Gunn rat, which has no B-UGT activity because it synthesizes a truncated enzyme (36) and which is an animal model for $\mathrm{CN}$ type I, phenobarbital treatment reduces serum bilirubin by $36 \%$ (37). In CN type I patients a small reduction of serum bilirubin upon phenobarbital treatment is sometimes also seen (4). The reduction of serum bilirubin after phenobarbital treatment in Gunn rats has been explained by a mobilization of bilirubin to the liver probably caused by the induction of cytosolic binding proteins such as ligandin (37). In type I patients similar mechanisms might play a role.

Although B-UGT1 (UGT1A) mRNA is not induced by phenobarbital in monkeys $(38)$, studies with human liver $(39,40)$ and studies with the human hepatoma HEPG2 (41) suggest that both B-UGT transcription and B-UGT activity are increased after phenobarbital treatment. Other factors such as alteration of the membrane environment or a stabilization of microsomal protein (42) might also play a role in the phenobarbital induced induction of B-UGT activity. The reduction of serum bilirubin levels after phenobarbital treatment observed in type II patients may thus be attributed to the induction of the mutated B-UGT1, which has enzyme activity, albeit at a reduced level.

Patients with residual B-UGT1 activity, CN type II, will benefit from mechanisms which increase B-UGT activity, whereas reduction of serum bilirubin in type I patients may be caused by the aspecific processes described above. The response a given $\mathrm{CN}$ patient, either type I or II, will have to phenobarbital treatment will depend on the way the different pathways are already induced.

The discrimination between type I and II CN should, in our opinion, be based on the presence of residual B-UGT1 activity in type II patients and the absence of activity in type I patients. This differentiation is clinically important for prognostication and for prediction of the need for liver transplantation. Our studies demonstrate that this differentiation can now be made by the identification of the mutations in B-UGT1 and the in vitro expression of the mutagenized B-UGT1.

In other inherited syndromes, such as lysosomal storage diseases, variability in clinical symptoms can also be understood as the consequence of differences in the residual activity of the affected enzymes (43).

The criterion of $>30 \%$ reduction of serum bilirubin after phenobarbital treatment for type II seems somewhat arbitrary. For the initial clinical diagnosis, however, it will remain an important tool.

\section{Acknowledgments}

Thanks to Dr. Alex Carmichael from Sydney, Australia for the bile sample and genomic DNA from patient B.

This work was partially supported by grants from the Crigler-Najjar foundation (to J. Seppen and C. T. M. Bakker) and the Netherlands Digestive Disease foundation (to J. Seppen), by the national institute of health grants RO1-DK 39137 (to N. Roy Chowdhury), RO1-DK 46057 (to J. Roy Chowdhury) and P30-DK 41296 (Liver Research Core Center), and from the March of Dimes Birth Diseases Foundation 6-FY93-0083 (to J. Roy Chowdhury).

\section{References}

1. Crigler, J. F., and V. A. Najjar. 1952. Congenital familial nonhemolitic jaundice with kernicterus. Pediatrics. 10:169-179.

2. Arias, I. M., L. M. Gartner, M. C. Cohen, J. Ben Ezzer, and A. J. Levi.
1969. Chronic nonhemolitic unconjugated hyperbilirubinaemia with glucuronyltransferase deficiency. Am. J. Med. 47:395-409.

3. Fevery, J., N. Blanckaert, K. P. M. Heirwegh, A-M. Preaux, and P. Berthelot. 1977. Unconjugated bilirubin and an increased proportion of bilirubin monoconjugates in the bile of patients with Gilbert's syndrome and CriglerNajjar disease. J. Clin. Invest. 60:970-979.

4. Sinaasappel, M., and P. L. M. Jansen. 1991. The differential diagnosis of Crigler-Najjar disease, types 1 and 2, by bile pigment analysis. Gastroenterology. 100:783-789.

5. Pett, S., and A. P. Mowat. 1987. Crigler-Najjar syndrome types I and II clinical experience-King's College Hospital 1972-1978. Phenobarbitone, phototherapy and liver transplantation. Mol. Aspects Med. 9:473-482.

6. Hunter, J. O., R. P. H. Thompson, P. M. Dunn, and R. Williams. 1973. Inheritance of type II Crigler-Najjar hyperbilirubinaemia. Gut. 14:46-49.

7. Gollan, J. L., S. N. Huang, B. Billing, and S. Sherlock. 1975. Prolonged survival in three brothers with severe type 2 Crigler-Najjar syndrome. Gastroenterology. 68:1543-1555.

8. Gentile, S., C. Del Vecchio Blanco, M. Persico, R. Marmo, and M. Coltori. 1986. Familial clustering of heterogeneous chronic unconjugated hyperbilirubinaemia. Hepato-Gastroenterology. 33:155-158.

9. Labrune, P., A. Myara, C. Hennion, J. P. Gout, F. Trivin, and M. Odievre. 1989. Crigler-Najjar type II disease inheritance: a family study. J. Inherited Metab. Dis. 12:302-306.

10. Robertson, K. J., D. Clarke, L. Sutherland, R. Wooster, M. W. H. Coughtrie, and B. Burchell. 1991. Investigation of the molecular basis of the genetic deficiency of UDP-glucuronosyltransferase in Crigler-Najjar syndrome. J. Inherited Metab. Dis. 14:563-579.

11. Ritter, J. K., F. Chen, Y. Y. Sheen, H. M. Tran, S. Kimura, M. T. Yeatman, and I. Owens. 1992. A novel complex locus UGT1 encodes human bilirubin UDP-glucuronosyltransferase isozymes with identical carboxyltermini. J. Biol. Chem. 267:3257-3261.

12. Jansen, P. L. M., G. J. Mulder, B. Burchell, and K. W. Bock. 1992. New developments in glucuronidation research: report of a workshop on glucuronidation, its role in health and disease. Gastroenterology. 15:532-544.

13. Bosma, P. J., N. Roy Chowdhury, B. G. Goldhorn, M. H. Hofker, R. P. J. Oude Elferink, P. L. M. Jansen, and J. Roy Chowdhury. 1992. Sequence of exons and the flanking regions of human bilirubin UDP-glucuronosyltransferase gene complex and identification of a genetic mutation in a patient with the CriglerNajjar syndrome, type I. Hepatology. 15:941-947.

14. Bosma, P. J., J. Roy Chowdhury, T. J. Huang, P. Lahiri, R. P. J. Oude Elferink, H. H. G. van Es, M. Lederstein, P. F. Whitington, P. L. M. Jansen, and N. Roy Chowdhury. 1992. Mechanisms of inherited deficiencies of multiple UDP-glucuronosyltransferase isoforms in two patients with Crigler-Najjar syndrome, type I. FASEB (Fed. Am. Soc. Exp. Biol.) J. 6:2859-2863.

15. Bosma P. J., B. Goldhoorn, R. P. J. Oude Elferink, M. Sinaasappel, B. A. Oostra, and P. L. M. Jansen. 1993. A mutation in bilirubin 5'-diphosphateglucuronosyltransferase isoform I causing Crigler-Najjar syndrome type II. Gastroenterology. 105:216-220.

16. van Es, H. H. G., B. G. Goldhoorn, M. Paul-Abrahamse, R. P. J. Oude Elferink, and P. L. M. Jansen. 1990. Immunochemical analysis of uridine diphosphate-glucuronosyltransferase in four patients with the Crigler-Najjar syndrome type I. J. Clin. Invest. 85:1199-1205.

17. Deng, W. P., and J. A. Nickoloff. 1992. Site directed mutagenesis of virtually any plasmid by eliminating a unique site. Anal. Biochem. 200:81-88.

18. Peters, W. H. M., W. A. Allebes, P. L. M. Jansen, L. G. Poels, and P. J. A Capel. 1987. Characterisation and tissue specificity of a monoclonal antibody against human uridine 5'-diphosphate glucuronosyltransferase. Gastroenterology. 93:162-169.

19. Gregoriadis, G. 1984. Liposome Technology, Volume I. CRC Press, Inc. Boca Raton, FL.

20. Fevery, J., N. Blanckaert, P. Leroy, R. Michiels, and K. P. M. Heirwegh. 1983. Analysis of bilirubins in biological fluids by extraction and thin layer chromatography of the intact tetrapyrroles: application to bile of patients with Gilbert's syndrome, hemolysis, or cholelithiasis. Hepatology. 3:177-183.

21. Spivak, W., and M. C. Cary. 1985. Reverse phase HPLC separation, quantification and preparation of bilirubin and its conjugates from native bile. Biochem. J. 225:787-805.

22. Crawford, J. M., B. J. Ransil, J. P. Narciso, and J. L. Gollan. 1992. Hepatic microsomal bilirubin UDP-glucuronosyltransferase. J. Biol. Chem. 267:1694316950.

23. Laemmli, U. K. 1970. Cleavage of structural proteins during the assembly of the head of bacteriophage T4. Nature (Lond.). 227:680-685.

24. Castell, J. V., M. Cervera, and R. Marco. 1979. A convenient micromethod for the assay of primary amines and proteins with fluorescamine. A reexamination of the conditions of reaction. Anal. Biochem. 99:379-391.

25. Tiribelli, C., and J. D. Ostrow. 1993. New concepts in bilirubin chemistry, transport and metabolism: report of the second international bilirubin workshop, April 9-11, 1992, Trieste, Italy. Hepatology. 17:715-736.

26. Zucker, S. D., J. Storch, M. L. Zeidel, and J. L. Gollan. 1992. Mechanism of the spontaneous transfer of unconjugated bilirubin between small unilamellar phosphatidylcholine vesicles. Biochemistry. 31:3184-3192. 
27. Noy, N., M. Leonard, and D. Zakim. 1992. The kinetics of interactions of bilirubin with lipid bilayers and with serum albumin. Biophys. Chem. 42:177188 .

28. Whitmer, D. I., P. E. Russell, and J. L. Gollan. 1987. Membrane-membrane interactions associated with rapid transfer of liposomal bilirubin to microsomal UDP-glucuronosyltransferase. Biochem. J. 244:41-47.

29. Magdalou, J., Y. Hochman, D. Zakim. 1982. Factors modulating the catalytic specificity of a pure form of UDP-glucuronyltransferase. J. Biol. Chem. 257:13624-13629.

30. Thapa, B. R., S. K. Yachna, and S. Mehta. 1987. Crigler-Najjar syndrome type II with kernicterus. Indian Pediatr. 24:680-683.

31. Wolff, H., G. Otto, and H. Giest. 1986. Liver transplantation in the CriglerNajjar syndrome. Transplantation. 42:84.

32. Duhamel, G., N. Blancaert, J. Metreau, A. Preaux, M. Bouvry, J. Fevery, and P. Berthelot. 1984. An unusual case of Crigler-Najjar disease in the adult J. Hepatol. 1:47-53.

33. Erps, L. T., J. K. Ritter, J. H. Hersch, D. Blossom, N. C. Martin, and I. S. Owens. 1994. Identification of two single base substitutions in the UGT1 gene locus which abolish bilirubin uridine diphosphate glucuronosyltransferase activity in vitro. J. Clin. Invest. 93:564-570.

34. Moghrabi, N., D. J. Clarke, M. Boxer, and B. Burchell. 1993. Identification of an A-toG missense mutation in exon 2 of the UGT1 gene complex that causes Crigler-Najjar syndrome type II. Genomics. 18:171-173.

35. Bosma, P. J., J. Seppen, B. Goldhoorn, C. Bakker, R. P. J. Oude Elferink, J. Roy Chowdhury, N. Roy Chowdhury, and P. L. M. Jansen. 1994. Bilirubin UDP-Glucuronosyltransferase 1 is the only relevant bilirubin glucuronidating isoform in man. J. Biol. Chem. 269:17960-17964.
36. Iyanagi, T. 1991. Molecular basis of multiple UDP-glucuronosyltransferase isoenzyme deficiencies in the hyperbilirubinaemic rat (Gunn rat). J. Biol. Chem. 266:24048-24052.

37. Cohen, A. N., J. Kapitulnik, J. D. Ostrow, E. A. Zenone, C. Cocrane, L. Celic, and H. Cheney. 1985. Effects of phenobarbital on bilirubin metabolism and its response to phototherapy in the jaundiced Gunn rat. Hepatology. 5:310316.

38. Ritter, J. K., J. M. Crawford, and I. S. Owens. 1991. Cloning of two human liver bilirubin UDP-glucuronosyltransferase cDNAs with expression in COS-1 cells. J. Biol. Chem. 266:1043-1047.

39. Bock, K. W., and B. S. Bock-Hennig. 1987. Differential induction of human liver UDP-glucuronosyltransferase activities by phenobarbital-type inducers. Biochem. Pharmacol. 36:4137-4143.

40. Sutherland, L., T. Ebner, and B. Burchell. 1993. The expression of UDPglucuronosyltransferases of the UGT1 family in human liver in response to drugs. Biochem. Pharmacol. 45:295-301.

41. Doostdar, H., M. H. Grant, W. T. Melvin, C. R. Wolf, and M. D. Burke. 1993. The effects of inducing agents on cytochrome P450 and UDP-glucuronosyltransferase activities in human HEPG2 hepatoma cells. Biochem. Pharmacol. 46:629-635.

42. Omura, T. 1979. Cytochrome P-450 linked mixed function oxidase turnover of microsomal components and effects of inducers on the turnover phospholipids, proteins and specific enzymes. Pharmacol. Ther. 8:489-499.

43. Leinekugel, P., S. Michel, E. Conzelmann, and K. Sandhoff. 1992. Quantitative correlation between the residual activity of b-hexosaminidase $A$ and arylsulfatase A and the severity of the resulting lysosomal storage disease. Hum. Genet. 88:513-523. 